\title{
Reply to the comments on 'Three-arm robot-assisted thoracoscopic surgery for locally advanced N2 non-small cell lung cancer', a better technique, new territory, and future hopes
}

\author{
Xinghua Cheng, Jia Huang, Jiantao Li, Peiji Lu, Qingquan Luo \\ Shanghai Chest Hospital, Shanghai Pulmonary Tumor Medical Center, Shanghai 200030, China \\ Correspondence to: Dr. Qingquan Luo. Shanghai Chest Hospital, Shanghai Pulmonary Tumor Medical Center, 241 West Huai-Hai Road, Shanghai \\ 200030, China. Email: qingquanluo@hotmail.com. \\ Response to: Phillips JD, Finley DJ. Editorial on expanded indications for robotic surgery in stage IIIA non-small cell lung cancer. J Thorac Dis \\ 2019;11:S1172-S1174. \\ Baste JM. Locally advanced N2 non-small cell lung cancer and the robotic platform: are we asking the right question? J Thorac Dis \\ 2019;11:S1184-S1185.
}

Submitted Sep 03, 2019. Accepted for publication Sep 16, 2019.

doi: $10.21037 /$ jtd.2019.09.57

View this article at: http://dx.doi.org/10.21037/jtd.2019.09.57

We thank Dr. Phillips et al. from the United States (1) and Dr. Baste from France (2) for their thoughtful comments on our recent article describing a case of clinical N2 nonsmall cell lung cancer (NSCLC) treated by robot-assisted thoracoscopic surgery (RATS). Both Dr. Phillips and Dr. Baste discussed the role of minimally invasive surgery in the treatment of locally advanced lung cancer. We agree that this group of NSCLCs is a composition of heterogeneous diseases including large tumors (T3 and $\mathrm{T} 4$ ) and tumors with nodal involvement. Thus, treatments for these patients are also complex (3). As these tumors are often adjacent to larger vessels and have higher odds of local recurrence, operation safety, and oncological efficacy should always be the primary consideration of surgical options (4). Although minimally invasive techniques may increase patients' tolerance to the later systematic therapy, they should only be considered by surgeons with enough experience when the primary standards can be met.

Dr. Phillips et al. briefly reviewed the current treatments of locally advanced lung cancer, and gave a concise introduction of their workflow for these patients as well as the RATS technique they used (1). There are several positive points worth noting in their clinical routine. (I) After primary evaluation for resectability, patients with $\mathrm{N} 2$ disease are recommended to be enrolled in clinical trials for induction therapy, which was decided by a multi-disciplinary team. For this group of patients, this is an especially important approach, because their survival rates are still poor regardless of which surgical technique is used (5). Whether and how the oncological outcomes can be improved by adding the new drugs, e.g., tyrosine kinase inhibitors and immune checkpoints inhibitors, to the current therapeutic regimen are urgent questions that can only be answered by intelligently designed trials (6,7). (II) As Dr. Phillips mentioned, more patients received RATS resection after the induction, suggesting this minimally invasive technique is safe and feasible in these patients in general, even after induction. Surgical outcomes and longterm survivals of these patients are of the interest to see. Moreover, unlike the 3-arm technique we used, they used a 4-arm approach to the new Xi platform. This latest platform further eases exposure and dissection due to better control by the surgeon and increased versatility of instrumentation. Such improvements should further ease adoption of the robotic tools.

Dr. Baste pointed out that the dissection of N1 nodes, but not the N2 nodes, may better reflect the superiority of RATS over the conventional thoracoscopic surgery. We fully agree that resections of these nodes are usually more challenging which requires extra caution even by very experienced surgeons. Although video-assisted thoracic surgery (VATS) surgeons also claim the ability to handle difficult lymph nodes safely and efficaciously, we believe the precision, improved version, and versatility of the RATS 
platform has and will continue to ease nodal dissection. Although there is still lack of direct evidence, recent studies showing more harvested nodes, lower conversion rate and satisfying survival rate by RATS in these patients may be indirect reflections of its ability (8-10). Besides dissection, suturing is another area that RATS may have remarkable advantages. It has become more widely accepted that bleeding control, bronchial reconstruction, and angioplasty are easier by RATS than by VATS (11). These techniques are clearly more often used in the treatment of locally advanced tumor. As Dr. Baste rightly pointed, standardization of these techniques as well as resolution to force feedback would hasten the spread of RATS. Dr. Baste also emphasized that it is the accessibility and cost of the RATS platform that impedes the diffusion of this technique. We have no doubt that if docking of the RATS platform was as easy as VATS and there was no extra cost, the conversion from RATS to VATS would be extremely fast. However, this is a widespread problem that most emerging techniques all face. So, let time do the job. RATS surgeons just keep calm and continue!

Again, we thank Dr. Phillips, Dr. Finley and Dr. Baste for their interest in our article. New drugs, more trials, better robots, and standardized procedures, these are the key elements that will drive future improvements in the surgical treatments of locally advanced NSCLC.

\section{Acknowledgments}

Funding: This work was supported by the Shanghai Hospital Development Center Grant (SHDC12016113) and Science and Technology Commission of Shanghai Municipality (18441901500).

\section{Footnote}

Conflicts of Interest: The authors have no conflicts of interest to declare.

Ethical Statement: The authors are accountable for all aspects of the work in ensuring that questions related to the accuracy or integrity of any part of the work are appropriately investigated and resolved.

\section{References}

1. Phillips JD, Finley DJ. Editorial on expanded indications for robotic surgery in stage IIIA non-small cell lung cancer. J Thorac Dis 2019;11:S1172-S1174.

2. Baste JM. Locally advanced N2 non-small cell lung cancer and the robotic platform: are we asking the right question? J Thorac Dis 2019;11:S1184-S1185.

3. Bryan DS, Donington JS. The Role of Surgery in Management of Locally Advanced Non-Small Cell Lung Cancer. Curr Treat Options Oncol 2019;20:27.

4. Cheng X, Onaitis MW, D'amico TA, et al. Minimally Invasive Thoracic Surgery 3.0: Lessons Learned From the History of Lung Cancer Surgery. Ann Surg 2018;267:37-8.

5. Veronesi G, Park B, Cerfolio R, et al. Robotic resection of Stage III lung cancer: an international retrospective study. Eur J Cardiothorac Surg 2018;54:912-9.

6. Zhong WZ, Chen KN, Chen C, et al. Erlotinib Versus Gemcitabine Plus Cisplatin as Neoadjuvant Treatment of Stage IIIA-N2 EGFR-Mutant Non-Small-Cell Lung Cancer (EMERGING-CTONG 1103): A Randomized Phase II Study. J Clin Oncol 2019;37:2235-45.

7. Forde PM, Chaft JE, Smith KN, et al. Neoadjuvant PD-1 Blockade in Resectable Lung Cancer. N Engl J Med 2018;378:1976-86.

8. Toker A, Özyurtkan MO, Demirhan Ö, et al. Lymph Node Dissection in Surgery for Lung Cancer: Comparison of Open vs. Video-Assisted vs. RoboticAssisted Approaches. Ann Thorac Cardiovasc Surg 2016;22:284-90.

9. Cerfolio RJ, Ghanim AF, Dylewski M, et al. The longterm survival of robotic lobectomy for non-small cell lung cancer: A multi-institutional study. J Thorac Cardiovasc Surg 2018;155:778-86.

10. Zirafa CC, Cavaliere I, Ricciardi S, et al. Long-term oncologic results for robotic major lung resection in nonsmall cell lung cancer (NSCLC) patients. Surg Oncol 2019;28:223-7.

11. Huang J, Li C, Jiang L, et al. Robotic-assisted thoracoscopic right upper lobe sleeve resection. J Thorac Dis 2019;11:243-45.

Cite this article as: Cheng $\mathrm{X}$, Huang $\mathrm{J}$, Li J, Lu P, Luo Q. Reply to the comments on 'Three-arm robot-assisted thoracoscopic surgery for locally advanced N2 non-small cell lung cancer', a better technique, new territory, and future hopes. J Thorac Dis 2019;11(10):E198-E199. doi: 10.21037/ jtd.2019.09.57 